\title{
PENDEKATAN PERILAKU KEUANGAN TERHADAP KEPUTUSAN INVESTASI EMAS
}

\author{
Johny Budiman, Ervina \\ Universitas Internasional Batam \\ Email: johnybdmn@gmail.com, ervinalee24@gmail.com
}

\begin{abstract}
This research aims to analyze the influence of representativeness, overconfidence, anchoring, loss aversion, and regret aversion towards gold investment decision. Sample of this study are gold investors in Batam. Hypothesis test using multiple regression. Results from this research showed that investors used representativeness, overcinfidence, and loss aversion to determine their investment decision in gold. But anchoring and regret aversion factors have no significant impact in their investment decision. Further research for investment decision could be conducted in financial sector.
\end{abstract}

Keywords: investment decision, representativeness, overconfidence, anchoring, loss aversion, regret aversion.

\begin{abstract}
ABSTRAK
Penelitian dilakukan untuk menganalisa perilaku representativeness, overconfidence, anchoring, loss aversion, dan regret aversion terhadap keputusan investasi emas. Sampel penelitian ini adalah investor yang berinvestasi emas di Kota Batam. Uji hipotesis menggunakan regresi berganda, Hasil dari riset menunjukkan investor lebih mengandalkan representativeness, overcinfidence, dan loss aversion dalam melakukan keputusan investasi emas. Namun faktor anchoring dan regret aversion terhadap keputusan investasinya secara signifikan tidak berdampak. Penelitian selanjutnya dapat dilakukan pada keputusan investasi di sektor finansial.
\end{abstract}

Kata kunci: keputusan investasi, representativeness, overconfidence, anchoring, loss aversion, regret aversion. 


\section{PENDAHULUAN}

Investasi merupakan salah satu cara untuk meraih laba dimasa yang akan datang. Emas merupakan logam mulia yang banyak diminati oleh investor harganya uang cenderung naik, selain mudah dicairkan atau memiliki tingkat likuidits yang tinggi.

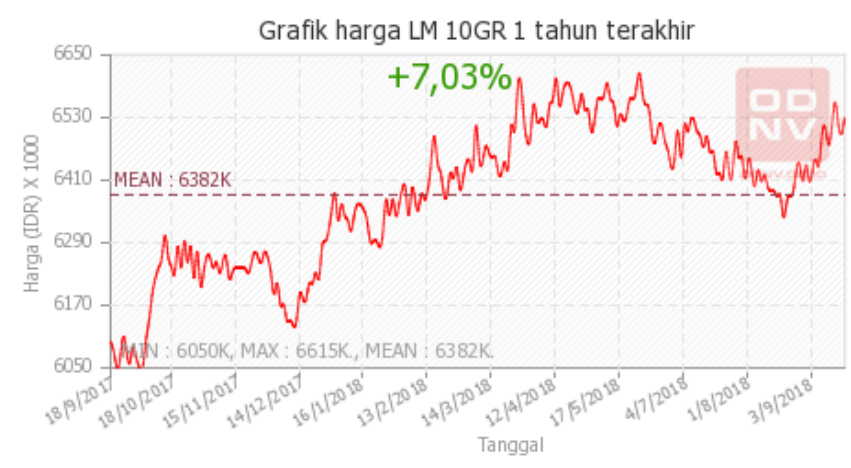

Gambar 1 Persentase kenaikan harga emas 1 tahun terakhir, sumber: odnv (2018).

Pada gambar grafik di atas, perkembangan emas satu tahun terakhir, harga emas mengalami kenaikan sebesar 7,03\%.

Tabel 1 Jumlah Investor Emas Pegadaian Cabang Mega Legenda Pertahun

\begin{tabular}{cc}
\hline Tahun & Jumlah (Orang) \\
\hline 2016 & 1.708 \\
2017 & 2.207 \\
2018 & 2.536 \\
\hline
\end{tabular}

Sumber: Pegadaian Mega Legenda (2018).

Dari data tersebut, diambil kesimpulan bahwa investor emas di Batam bertambah setiap tahunnya. Dan untuk investor emas di Kota Batam diperkirakan mencapai sekitar 20.000 orang. Jika dibandingkan dengan Bali, investor emas di Batam hanya 50\% dari jumlah investor emas di Bali, yaitu 40.185 (Tempo, 2018). Jika dibandingkan dengan jumlah penduduk Kota Batam berdasarkan sensus penduduk 2018 adalah 1.329.773 jiwa, artinya hanya $1,5 \%$ penduduk yang merupakan investor Emas di Kota Batam. Padahal, harga emas yang terus naik dan emas dan memiliki risiko yang kecil seharusnya membuat masyarakat berminat untuk berinvestasi emas. Namun, data menunjukkan hanya sebagian kecil masyarakat yang berinvestasi emas.
Penelitian ini menarik untuk diteliti karena disatu sisi harga emas yang trendnya terus mengalami kenaikkan, namun disisi lain minat investor yang meliriknya masih rendah.Dengan demikian menjadi penting untuk diketahui perilaku investor dari sisi keuangan dalam melakukan keputusan investasi emas di kota Batam.

\section{B. KAJIAN PUSTAKA}

\section{Representativeness}

Representativeness

berpengaruh secara signifikan terhadap keputusan investasi karena investor membuat keputusan untuk berinvestasi berdasarkan pengalaman masa lalu. Badshah, et al. (2016),Subramaniam dan Velnampy (2017), Antony dan Joseph (2017), Pandey dan Jessica (2018), dan Rasheed, et al. (2018), ) mengungkapkan bahwa representativeness memberikan pengaruh signifikan positif terhadap keputusan investasi. Karena investor kurang informasi dan kurang pengetahuan tentang investasi sehingga cenderung menarik kesimpulan dengan cepat dan membuat keputusan investasi berdasarkan pengalaman masa lalu, namun hal ini bisa menjadi keputusan yang keliru.

\section{Overconfidence}

Mumaraki dan Nasieku (2016), Antony dan Joseph (2017), dan Javed dan Marghoob (2017) dalam risetnya menunjukkan hasil yang konsiten bahwa overconfidence memiliki pengaruh signifikan positif terhadap keputusan investasi. Para investor memanfaatkan kepercayaan diri mereka dengan menggunakan pengetahuan dan keterampilan yang dimiliki guna meningkatkan hasil yang akan didapat dari berinvestasi. Diungkapkan bahwa orang-orang cenderung terlalu percaya diri dengan prediksi dan hasil yang akan diperoleh dari investasi. Semakin orang memiliki kepercayaan diri yang tinggi, maka semakin ia yakin bahwa investasinya akan menghasilkan laba

\section{Anchoring}

Donkor, Akohene dan Acheampong (2016), Javed dan Marghoob (2017), Usman et al. (2017), dan Pandey dan Jessica (2018) membuktikan dalam penelitiannya bahwa anchoring berdampak signifikan positif terhadap keputusan investasi. Hal ini terjadi 
karena biasanya evaluasi investor cenderung berpedoman kepada nilai awal yang telah diberikan dan umumnya investor akan mempertahankan investasi yang memiliki kinerja yang baik dalam investasi mereka.

\section{Loss Aversion}

Alquraan, Alqisie dan Al Shorafa (2016), Gupta dan Ahmed (2016), Pandey dan Jessica (2018) menyimpulkan bahwa loss aversion memiliki pengaruh signifikan positif terhadap keputusan investasi. Investor akan mencoba untuk menghindari kerugian terlebih dahulu daripada menngharapkan keuntungan yang akan didapat dari investasi. Lebih lanjut, Subramaniam dan Velnampy (2017) mengungkapkan bahwa loss aversion mempengaruhi keputusan investor yang telah berumah tangga di Sri Lanka. Karena para investor lebih memperhatikan keamanan uang mereka daripada berupaya memperoleh keuntungan. Mereka cenderung mengambil risiko yang lebih besar untuk menghindari kerugian daripada menghasilkan lebih banyak keuntungan.

\section{Regret Aversion}

Hasil penelitian Gupta dan Ahmed (2016). Antony dan Joseph (2017), Subramaniam dan Velnampy (2017), dan Pandey dan Jessica (2018), mengatakan bahwa keputusan investor dipengaruhi oleh regret aversion. Karena secara umum investor melakukan investasi untuk kepentingan jangka panjang sehingga jika hasil dari investasi negatif maka akan menjadi hal yang sensitif bagi para investor dan dihindari.

\section{METODE PENELITIAN}

Penelitian ini merupakan penelitian dasar, dengan tujuan mengembangkan teori yang telah ada, menggunakan karakteristik sebab-akibat yaitu representativeness, overconfidence, anchoring, loss aversion, dan regret aversion yang mempengaruhi keputusan investasi emas.

Populasi riset adalah investor emas di Kota Batam dengan sampel sebesar 170 responden. Pengambilan sampel dengan menggunakan metode Hair, et al.(2010) yaitu jumlah minimum sampel diambil dari jumlah pertanyaan yaitu 85 orang, untuk menghindari kuesioner yang tidak diisi lengkap, rusak dan tidak dikembalikan maka penulis menaikkan sampel menjadi 170 orang. Data penelitian merupakan data primer, dengan menggunakan purposive sampling dalam pemilihan sampel. Kriteria responden dalam penelitian ini adalah responden yang melakukan investasi berupa logam mulia batangan dan melakukan transaksi jual dan beli logam mulia di Kota Batam.

Horizon waktu dalam penelitian ini menggunakan studi satu tahap, yaitu data dikumpulkan secara sekaligus untuk penelitian dan membandingkan hasilnya dengan pertanyaan lain atau mengukur korelasi antar jawaban. Jawaban kuesioner yang terkumpul kemudian dianalisis dengan linear berganda.

\section{HASIL DAN PEMBAHASAN}

Data responden yang dipakai berjumlah 164 dari 170 kuesioner yang disebarkan kepada masyarakat yang berinvestasi emas dari berbagai kecamatan dan kalangan di Kota Batam. Responden menurut jenis kelamin adalah 68 orang (41,5\%) responden pria, sedangkan responden berjenis kelamin wanita adalah 96 orang $(58,5 \%)$. Ratarata responden berumur 26-30 tahun (55,5\%). Status responden menunjukkan sebanyak 107 orang $(65,2 \%)$ telah menikah. Terdapat $30,5 \%$ dengan tingkat pendidikan terakhirnya adalah SMA sederajat, dan didominasi $58,5 \%$ untuk sarjana. Untuk profil pendapatan, didominasi jumlah pendapatan Rp3 juta-Rp5 juta sebanyak 123 responden $(75 \%)$.

\section{Hasil Uji Hipotesis Hasil Uji F}

Pengujian validitas dan reliabilitan didapatkan hasil bahwa semua pernyataan dinyatakan valid dan reliabel oleh karena itu semua pernyataan akan diikut sertakan dalam proses pengujian data lebih lanjut.

Hasil uji F disimpulkan bahwa model regresi layak dipakai dalam memperkirakan keputusan investasi (nilai signifikansi adalah $0,000<0,05$

Tabel 2 Hasil Uji F

\begin{tabular}{ccc}
\hline Model & Sig. & Keterangan \\
\hline Regression & 0,000 & Signifikan \\
\hline Sumber: Data Primer Diolah & $(2018)$
\end{tabular}


Hasil Uji t

Hasil uji t terdapat pada Tabel 3

Tabel 3 Hasil Uji t

\begin{tabular}{lccc}
\hline \multicolumn{1}{c}{ Variabel } & B & Sig & $\begin{array}{c}\text { Keterang } \\
\text { an }\end{array}$ \\
\hline Representative & 0,41 & 0,00 & Signifikan \\
ness & 8 & 0 & positif \\
Overconfidence & 0,15 & 0,02 & Signifikan \\
& 1 & 9 & Positif \\
Anchoring & - & 0,32 & Tidak \\
& 0,08 & 4 & signifikan \\
Loss Aversion & 0,19 & 0,00 & Signifikan \\
& 9 & 6 & positif \\
Regret & - & 0,36 & Tidak \\
Aversion & 0,08 & 9 & signifikan \\
& 0 & & \\
\hline
\end{tabular}

Sumber: Data Primer Diolah (2018).

Berdasarkan hasil uji t, dapat dijelaskan masing-masing hipotesis sebagai berikut:

Berdasarkan uji t diketahui bahwa nilai signifikansi variabel representativeness sebesar $0,000<0,05$ dan nilai standardized coefficients beta 0,418 . Hasil ini menunjukkan representativeness memiliki hubungan signifikan positif terhadap keputusan investasi emas masyarakat di Kota Batam. Temuan ini menunjukkan bahwa investor cenderung berpedoman dengan pengalaman masa lalu dan dengan cepat menarik kesimpulan dalam membuat keputusan investasi. Hasil temuan ini konsisten dengan penelitian dari Pandey dan Jessica (2018), Rasheed et al. (2018), Subramaniam dan Velnampy (2017), Antony dan Joseph (2017), dan Badshah et al. (2016).

Berdasarkan hasil uji statitistik nilai signifikansi variabel overconfidence sebesar $0,029<0,05$ dan standardized coefficients beta adalah 0,151. Overconfidence memiliki pengaruh signifikan positif terhadap keputusan investasi. Temuan ini menunjukkan bahwa investor dipengaruhi oleh tingkat kepercayaan diri yang tinggi dalam membuat keputusan investasi. Tingkat kepercayaan diri yang tinggi ini membuat investor sangat yakin dengan laba yang akan diperoleh dari investasinya, sehingga semakin besar pula investasi yang dilakukan. Hasil riset ini sejalan dengan hasil riset sebelumnya dari Antony dan Joseph (2017), Javed dan Marghoob (2017), dan Mumaraki dan Nasieku (2016)
Berbeda dengan variabel anchoring yang mempunyai nilai uji sebesar $0,324>0,05$ dan memiliki standardized coefficients beta sebesar -0,087. Hasil ini berarti bahwa variabel anchoring tidak berpengaruh terhadap keputusan investasi emas masyarakat di Kota Batam. Dapat diketahui bahwa investor di Kota Batam tidak terpengaruh oleh nilai awal yang diberikan dalam membandingkan dengan nilai yang akan datang. Hasil temuan ini tidak konsisten dengan Pandey dan Jessica (2018), Javed dan Marghoob (2017), dan Usman et al. (2017).

Terdapat pengaruh yang signifikan dan positif untuk variabel loss aversion yaitu sebesar 0,006 $<0,05$ dan nilai standardized coefficients beta 0,199. Loss aversion berhubungan signifikan positif terhadap keputusan investasi emas masyarakat di Kota Batam. Dengan demikian bisa disimpulkan bahwa penghindaran dari kerugian akan berdampak positif terhadap keputusan investasi emas masyarakat di Kota Batam. Investor cenderung mengambil risiko untuk menghindari kerugian daripada mencoba untuk mendapatkan lebih banyak keuntungan. Hasil temuan ini konsisten dengan penelitian dari Subramaniam dan Velnampy (2017), Alquraan et al. (2016), dan Gupta dan Ahmed (2016).

Untuk nilai signifikansi variabel regret avesion terhadap keputusan investasi adalah $0,369>0,05$ dan nilai standardized coefficients beta -0,080. Regret aversion tidak memiliki pengaruh yang signifikan terhadap keputusan investasi emas masyarakat di Kota Batam. Ketakutan akan penyesalan tidak mempengaruhi keputusan investasi, karena keputusan tersebut dibuat oleh investor sendiri. Hasil temuan ini tidak konsisten dengan Pandey dan Jessica (2018), Subramaniam dan Velnampy (2017), Antony dan Joseph (2017), dan Gupta dan Ahmed (2016).

\section{Hasil Uji Koefisien Determinasi $\left(\mathbf{R}^{\mathbf{2}}\right)$}

Nilai adjusted $\mathrm{R}^{2}$ adalah 0,263 , artinya variabel independen atau bebas mampu menjelaskan $26,3 \%$ variabel keputusan investasi sedangkan sisanya $73,7 \%$ diterangkan oleh faktor lain yang tidak terdapat di dalam model.

Tabel 4 Hasil Uji Koefisien Determinasi $\left(\mathbf{R}^{2}\right)$

\begin{tabular}{ccc}
\hline Model & R Square & $\begin{array}{c}\text { Adjusted } \mathbf{R} \\
\text { Square }\end{array}$ \\
\hline Regression & 0,286 & 0,263 \\
\hline Sumber: Data Primer Diolah (2018).
\end{tabular}




\section{E. KESIMPULAN DAN SARAN Kesimpulan}

Representativeness, Overconfidence dan loss adversion berpengaruh signifikan dan positif terhadap keputusan investasi emas. Investor cenderung mengandalkan pengalaman masa lalu dan kepercayaan diri yang berlebihan, dan cenderung menghindari kerugian dalam investasi daripada berusaha memperoleh keuntungan yang akan diperolehnya. Investor yang mempunyai pengalaman investasi yang bagus, rasa percaya dirinya akan terus meningkat, yang pada akhirnya semakin banyak melakukan investasi dalam emas.

\section{Rekomendasi}

Berdasarkan hasil penelitian, investor harus mempertimbangkan perilaku Representativeness, oveconfidence dan loss adversion khususnya dalam melakukan investasi dalam emas. Namun pengalaman masa lalu dan kepercayaan diri yang berlebih ini juga harus bijak disikapi. Penelitian selanjutnya dapat mempertimbangkan faktor lainnya dalam investasi baik disektor rill maupun sektor finansil terutama untuk jangka waktu yang panjang.

\section{F. DAFTAR PUSTAKA}

Alquraan, T., Alqisie, A., \& Shorafa, A. A. (2016). Do behavioral finance factors influence stock investment decisions of individual investors? (evidences from Saudi stock market). American International Journal of Contemporary Research, 6(3), 159-69.

Antony, A., \& Joseph, A. I. (2017). Influence of behavioural factors affecting investment decision-An AHP analysis. Indian Institute of Management, Lucknow, 16(2), 107-114. DOI:10.1177/0972622517738833.

Badshah, W., Irshad, S., \& Hakam, U. (2016). Effect of representativeness bias on investment decision making. Management and Administrative Sciences Review, 5(1): 26-30.

Donkor, J., Akohene, V., \& Acheampong. S. (2016). Behavioural factors and investment decisions of bankers in Ghana. British Journal of Education, Society \& Behavioural Science, 18(3), 18. DOI: 10.9734/BJESBS/2016/23353
Gupta, Y., \& Ahmed, S. (2016). The impact of psychological factors on investment decision making of investors: An empirical analysis. EPRA International Journal of Economic and Business Review, 4(11), 40-52.

Hair, J. F., Black, W. C., Babin, B. J., \& Anderson, R. E. (2010). Multivariate Data Analysis. Vectors.

Javed, M. A., \& Marghoob. S. (2017). The effects of behavioural factors in investment decision making at Pakistan stock exchanges. Journal of Advanced Research in Business and Management Studies, 7 (1), 103-14.

Mumaraki, J. N., \& Nasieku, T. (2016). Effect of overconfidence on individual investment decision: Evidence from the investment services sector in Kenya. The International Journal of Business and Management, 4(10), 254-261.

Odnv. (2018). Grafik Fluktuasi Harga LM Emas Antam. Retrieved from www.odnv.co.id

Pandey, R., \& Jessica, V. M. (2018). Measuring behavioural biases affecting real estate investment decisions in India : Using IRT. International Journal of Housing Market and Analysis. Http://doi.org/10.1108/IJHMA-12-20170103.

Rasheed, M. H., Rafique, A., Zahid, T., \& Akhtar, M. W. (2018). Factor influencing investor's decision making in Pakistan: Moderating the role of locus of control. Review of Behavioral Finance. Http://doi.org/10.1108/RBF-05-20160028.

Subramaniam, A., \& Velnampy, T. (2017). The role of behavioural factors in the investment decisions of household investors. International Journal of Accounting and Financial Reporting, 7(1), 392-412. DOI: 10.5296/ijafr.v7i1.11421

Tempo. (2018). Minat Warga Bali Investasi Emas Naik, Ini Sebabnya. Retrieved from https://bisnis.tempo.co/read/1060749/mi nat-warga-bali-investasi-emas-naik-inisebabnya. 
Usman, D. I., Muturi, W. M., \& Memba, F. S. (2017). Influence of anchoring bias on investor's decision making in property market in Plateau state, Nigeria. International Journal of Management and Commerce Innovations, 5(1), 49-59. 